\title{
Os estudantes beneficiários do Programa Bolsa Família no contexto da educação pública do Paraná: uma leitura a partir das mesorregiões do estado
} Students benefiting from the Bolsa Familia Program in the context of public education in Paraná: a reading from the mesoregions of the state

\section{Los estudiantes beneficiarios del Programa Bolsa Familia en el contexto de la educación pública de Paraná: una lectura a partir de las mesorregiones del estado}

\author{
Andréa Barbosa Gouveia ${ }^{1}$ \\ Gabriela Schneider ${ }^{1}$
}

DOI: http://dx.doi.org/10.20435/serie-estudos.v22i46.1046

\begin{abstract}
Resumo: O Programa Bolsa Família (PBF) tem sido um importante aliado na redução da pobreza e na diminuição da desigualdade social. Além disso, por meio da condicionalidade escolar, tem colaborado com a permanência de crianças e jovens na escola, o que representa um importante passo na garantia do direito à educação. Esse direito, contudo, não se limita ao acesso, e, nesse sentido, a análise de onde estão esses estudantes e quais as escolas que frequentam é essencial. Neste artigo, analisam-se os estudantes beneficiários do PBF a partir do recorte das mesorregiões do Paraná, buscando caracterizar o volume de estudantes beneficiários, as condições gerais da região e as condições especificamente de oferta escolar, considerando tipo de vínculo dos professores, formação dos professores e estrutura material da escola. Os resultados sugerem uma relação entre melhores condições docentes, em termos de formação ou vínculo de trabalho com o menor percentual de beneficiários do programa, o que também pode ser percebido no que se refere à estrutura material, ainda que com algumas diferenças dentro das diversas regiões. O Centro Sul apresenta-se como uma das regiões com o maior número de beneficiários em relação à matrícula e também com as condições mais precárias.
\end{abstract}

Palavras chaves: política educacional; Programa Bolsa Família; mesorregiões paranaenses.

Abstract: The Bolsa Família Program (PBF) has been an important ally in the reduction of poverty and in the reduction of social inequality; in addition, through school conditionality, it has collaborated with the permanence of children and young people in school, which represents an important step in guarantee the right to education. The right, however, is not limited to access, and in that sense the analysis of where these students are and which schools they attend is essential. In this article, we

${ }^{1}$ Universidade Federal do Paraná (UFPR), Curitiba, Paraná, Brasil. 
analyze the students who are beneficiaries of the PBF from the view of the mesoregions of Paraná, seeking to characterize the volume of beneficiary students, the general conditions of the region and the specific conditions of school supply, considering the type of teacher work contract, teacher training and school structure material. The results suggest a relationship between better teaching conditions, in terms of training or work contract type with the lowest percentage of program beneficiaries, as well this can also be perceived regarding the material structure, although with some differences within the diverse regions. The South Center is one of the regions with the largest number of beneficiaries in relation to enrollment and also in the most precarious conditions.

Key words: educational policy; the Bolsa Família Programme; mesoregions of Paraná.

Resumen: El Programa Bolsa Familia (PBF) ha sido un aliado importante en la reducción de la pobreza y de la desigualdad social, por otra parte, a través de la condicionalidad de la escuela ha colaborado con la permanencia de los niños y jóvenes en la escuela, que es un importante paso para garantizar el derecho a la educación. El derecho, sin embargo, no se limita al acceso, y en este sentido el análisis de donde estan estes studiantes y cual son las escuelas en que estudian es esencial. En este artículo se analizan los beneficiarios de PBF por el recorte de las mesoregioenes de la Provincia del Paraná, donde se busca caracterizar el volumen de alumnos beneficiarios, las condiciones generales de la región y las condiciones de la oferta escolar teniendo en cuenta el tipo de enlace de los maestros, la formación del profesorado y la estructura de la escuela. Los resultados sugieren una relación entre mejores condiciones de los profesores, sea en la formación o el tipo de contrato de trabajo con el menor porcentaje de los beneficiarios del programa, sino que también puede ser visto en relación con la estructura, aunque con algunas diferencias al interior de los distintos regiones. El Centro del Sur se presenta como una de las regiones con el mayor número de beneficiarios en relación con el registro y también las condiciones más precarias.

Palabras clave: política educacional; Programa Bolsa Familia; mesorregiones Paraná.

Analisar a efetividade da política educacional requer sempre que se considere a quem se destina a política. Nesse contexto, compreender a dimensão de renda dos estudantes das escolas públicas significa reconhecer que os estudantes pobres estão na escola, e isto explicita a necessidade de a escola promover continuamente uma experiência de inclusão, no sentido mais pleno do conceito. Cury adverte que a educação básica constitui direito pleno, mas que só poderá ser efetivo quando o país:

Oferecer a toda sua população reais condições de inclusão na escolaridade e na cidadania, [...] ao invés de mostrar apenas a face perversa e dualista de um passado ainda em curso, poderá efetivar o princípio da igualdade de oportunidades de modo a revelar méritos pessoais e riquezas insuspeitas de um povo e de um Brasil uno em sua multiplicidade, moderno e democrático. (CURY, 2000, p. 81).

A que distância estamos desse passado de dualidades? Este artigo pretende contribuir para essa reflexão ao analisar os estudantes pobres no contexto da educação pública paranaense. O conceito de pobreza aqui se refere especificamente aos estudantes que compõem o grupo de beneficiários do Programa Bolsa Família a partir 
dos dados do Sistema Presença que acompanha a condicionalidade de frequência à escola para a efetividade da proteção da renda. De acordo com Sen (2012), analisar a questão da pobreza é um elemento central na maioria das sociedades, contudo ele aponta a necessidade de que esta não se restrinja apenas à questão da renda, mas pense também na capacidade de conversão dessa renda em condições de vida.

Olhar a pobreza em termos de recursos financeiros (ou da falta deles), apesar de importante não é suficiente, pois ela em geral é acompanhada de outras desigualdades, nem sempre captadas por esse elemento. Nesse sentido, ao olhar as condições das escolas a que estão submetidos os estudantes beneficiários do Programa Bolsa Família, passa-se a uma análise mais ampla da própria pobreza, pois se entende que "[...] a pobreza real (com relação à privação de capacidade) pode facilmente ser muito mais intensa do que podemos deduzir dos dados sobre renda" (SEN, 2011, p. 291).

A partir do tratamento do banco de dados do Sistema Presença e do cotejamento deste com o Censo Escolar, e com dados do Atlas do Desenvolvimento Humano, é possível caracterizar as condições de contextos municipais em que os estudantes estão inseridos. Os contextos escolares são explorados a partir de variáveis de condições de oferta relativas à estrutura das escolas e aos professores. Tais cotejamentos visam aprofundar o conhecimento sobre onde estão os estudantes beneficiários do PBF no estado e em que condições o cumprimento da condicionalidade da frequência à escola tem se constituído.

Para essa análise, cabe inicialmente considerar quantos são os estudantes beneficiários do Programa Bolsa Família no ensino fundamental no Paraná e para quantos estudantes há informações consolidadas no banco de dados. Esse contexto requer observar-se inicialmente o tamanho geral do programa Bolsa Família no Paraná e o número de crianças e adolescentes protegidos. Para esse panorama, tomam-se também os dados do Ministério do Desenvolvimento Social disponível no Cadastro único para Programas Sociais, tanto no Brasil, quanto no Paraná. Apesar de o artigo tratar de uma leitura a partir dos dados de 2015, parece pertinente contextualizar o movimento do programa. Para isto, tomam-se os dados dos três últimos anos, disponíveis no site do Ministério do Desenvolvimento Social e Combate à Fome (MDS). A tabela 1 sintetiza tais dados: 
Tabela 1: Beneficiários do Programa Bolsa Família, Brasil e Paraná, 2013 a 2015

\begin{tabular}{ccccccc}
\hline Beneficiários & 2013 & $\%$ & 2014 & $\%$ & 2015 & $\%$ \\
\hline Total & & & & & & \\
Brasil & 47.996 .690 & & 48.642 .544 & & 47.148 .453 & \\
Paraná & 1.473 .608 & 3,07 & 1.452 .597 & 2,99 & 1.362 .336 & 2,89 \\
de 04 a 06 anos & & & & & & \\
Brasil & 3.893 .655 & 8,11 & 3.971 .120 & 8,16 & 3.921 .991 & 8,32 \\
Paraná & 122.257 & 8,30 & 124.507 & 8,57 & 120.824 & 8,87 \\
De 7 a 14 anos & & & & & & \\
Brasil & 11.776 .535 & 24,54 & 11.624 .633 & 23,90 & 11.037 .809 & 23,41 \\
Paraná & 369.012 & 25,04 & 352.680 & 24,28 & 321.234 & 23,58 \\
\hline
\end{tabular}

Fonte: MDS, Cadastro Único para Programas Sociais (CadÚnico) MDS, Folha de Pagamentos do Programa Bolsa Família (PBF) - 2013-2016

Observe-se que, no Paraná, estão cerca de 3\% dos sujeitos beneficiários do Programa Bolsa Família no país (3,07\% em 2013 e 2,89\% em 2015). Porém, quando consideramos o percentual de crianças e adolescentes em idade de escolarização obrigatória, esse percentual é muito próximo do nacional, ou seja, ainda que o programa possa ser pequeno no Paraná, a composição deste, considerando o corte etário, é similar ao nacional.

Assim, aproximadamente um quarto dos beneficiários do Programa Bolsa Família estão em idade de educação obrigatória. Observando os dados da tabela 1 , é possível perceber que, em 2013, eram 25,04\% os beneficiários de 7 a 14 anos no Paraná, e, em 2015, 23,58\%. Tanto no Brasil, quanto no Paraná, há diminuição de beneficiários nessa faixa etária. O volume de sujeitos protegidos pelo PBF justifica que é preciso considerar que condições de escola têm sido garantida para esses sujeitos, haja vista o entendimento de que a redução da pobreza passa necessariamente pelo incremento da renda, mas não se esgota nela (SEN, 2012).

Para analisar as condições de oferta, é necessário articular as informações sobre os beneficiários e suas escolas. O cotejamento dos dados do Sistema Presença, em 2015², e do Censo Escolar 2015 resultam em um banco de dados com informações equivalentes a 73\% dos estudantes de 7 a 14 anos que integram o PBF. Considerando que o Censo Escolar de 2015 (INEP, 2015) registra 5.172 estabelecimentos escolares de ensino fundamental, com oferta de anos iniciais, anos finais ou de ensino funda-

\footnotetext{
${ }^{2}$ Os dados do Sistema Presença são coletados bimestralmente, sendo que, em cada ano, têm-se informações de frequência em nove meses do ano (de fevereiro a novembro), contudo opta-se por trabalhar apenas com os dados referentes ao mês de maio, que é o período de coleta de informações do censo escolar.
} 
Os estudantes beneficiários do Programa Bolsa Familia no contexto da educação pública do Paraná: uma leitura a partir das mesorregiões do estado

mental completo, os dados da tabela 2 evidenciam que há um número expressivo de escolas paranaenses em que estão presentes estudantes cujas famílias integram o PBF.

Tabela 2: Número de escolas e estudantes beneficiários do PBF, Paraná, 2015.

Informações no banco de dados consolidado
Número
de escolas
Total de

estudantes
$\%$ sobre o total de

Beneficiários**

(7 a 14 anos)

\section{Anos iniciais do Ensino Fundamental \\ Anos finais do Ensino Fundamental \\ Total \\ 2.959 \\ 1.911 \\ 4.870 \\ 99.967 \\ 136.414 \\ 236.381}

$73 \%$

Fonte: Banco de dados do Sistema Presença (2015)

* alguns estabelecimentos ofertam anos iniciais e finais do ensino fundamental.

**são 321.234 beneficiários no Paraná no ano de 2015.

O regime de colaboração no estado do Paraná tem como característica a predominância da oferta dos anos iniciais do ensino fundamental nas redes municipais e dos anos finais do ensino fundamental na rede estadual. No ano de 2015, a rede estadual respondia por $89 \%$ da matrícula nos anos finais, enquanto o conjunto das redes municipais respondia por apenas 2\%; e, o oposto no caso dos anos iniciais, a rede estadual respondia por 0,5\% da matrícula, e o conjunto das redes municipais respondia por 83\% da matrícula (INSTITUTO NACIONAL DE ESTUDOS E PESQUISAS EDUCACIONAIS ANÍSIO TEIXEIRA [INEP], 2015). Diante desse quadro, a opção metodológica para esta análise foi de organizar o banco de dados separando os beneficiários dos anos iniciais e dos anos finais. Dessa forma, a análise recairá sobre a oferta predominante em cada rede de ensino, ou seja, ao analisarmos os anos iniciais estaremos nos referindo às redes municipais e, quando analisarmos os anos finais, estaremos nos referindo à rede estadual de ensino.

\section{CARACTERÍSTICAS DAS MESORREGIÕES DO PARANÁ E OS BENEFICIÁRIOS DO PROGRAMA BOLSA FAMÍLIA}

A divisão territorial por mesorregião foi conceitualmente criada pelo Instituto Brasileiro de Geografia e Estatística (IBGE), cuja função é a subdivisão dos municípios dentro do mesmo Estado que apresentem características econômicas e sociais semelhantes. O Paraná conta com 10 mesorregiões que abarcam os 399 municípios do Estado, as mesorregiões paranaenses são: Centro Sul, Centro Ocidental, Norte Pioneiro, Sudeste, Sudoeste, Centro Oriental, Noroeste, Norte Central, Oeste e Metropolitana, as quais a presentam características distintas, seja em termos sociais, econômicos e mesmo educacionais. 
No que se refere aos beneficiários do Programa Bolsa Família, as regiões apresentam uma divisão bastante relacionada à concentração populacional, pois a região metropolitana de Curitiba é a que congrega o maior percentual de beneficiários, tanto nos anos iniciais como finais do Ensino Fundamental, sendo que essa mesorregião tem 33,5\% da população paranaense. A região Centro Ocidental é a com a menor taxa populacional, 3,2\% e a que possui o menor percentual de beneficiários. Contudo, ao analisar o quanto são os beneficiários em relação ao total da matrícula, a situação é bastante diversa, pois a região Centro Sul, Norte Pioneiro e Centro Oriental são as que têm a maior parte de seus estudantes vinculados ao PBF, como pode se observar na tabela abaixo.

Tabela 3 - Percentual de beneficiários do programa bolsa família nos anos iniciais e anos finais do Ensino Fundamental, Paraná, 2015.

\begin{tabular}{ccccc}
\hline & $\begin{array}{c}\text { \% de beneficiários dos } \\
\text { AI do EF em relação ao } \\
\text { total do Estado }\end{array}$ & $\begin{array}{c}\text { \% de } \\
\text { beneficiários } \\
\text { nos AI do EF }\end{array}$ & $\begin{array}{c}\text { \% de beneficiários } \\
\text { em relação ao total do } \\
\text { Estado AF do EF }\end{array}$ & $\begin{array}{c}\text { \% de } \\
\text { beneficiários } \\
\text { nos AF do EF }\end{array}$ \\
\hline Centro Ocidental & 4,50 & 22,1 & 4,1 & 30,9 \\
Centro Oriental & 8,07 & 15,8 & 9,2 & 28,0 \\
Centro Sul & 10,02 & 23,5 & 12,1 & 44,8 \\
Metropolitana & 28,01 & 12,2 & 25,2 & 19,5 \\
Noroeste & 5,76 & 13,8 & 5,0 & 19,8 \\
Norte Central & 15,22 & 13,3 & 14,1 & 20,1 \\
Norte Pioneiro & 7,45 & 21,3 & 6,6 & 30,7 \\
Oeste & 10,84 & 13,2 & 10,9 & 21,6 \\
Sudeste & 5,48 & 18,1 & 7,0 & 37,6 \\
Sudoeste & 4,67 & 14,5 & 5,9 & 28,0 \\
\hline
\end{tabular}

Fonte: Banco de dados do Sistema Presença (2015); Microdados do Censo Escolar (2015).

A concentração de estudante ser superior nas regiões supracitadas indica que o programa tem sido efetivo nas localidades em que é mais necessário, haja vista que o Centro Sul, o Norte Pioneiro e o Centro Oriental têm o maior número de municípios com os valores mais baixo do Índice de Desenvolvimento Humano Municipal do Paraná. No Centro Sul, 48,8\% das crianças são consideradas pobres ou extremamente pobres ${ }^{3}$, segundo definição do Atlas do Desenvolvimento Humano (dados de 2010).

\footnotetext{
${ }^{3}$ Segundo definição do Atlas do Desenvolvimento Humano, as crianças extremamente pobres são aquelas com idade até 14 anos que têm renda domiciliar per capita igual ou inferior a 70 reais mensais em agosto de 2010. Já as crianças pobres são classificadas como aquelas que têm renda familiar per capital igual ou inferior a 140 reais mensais. Os dados se referem apenas aos indivíduos com residência permanente.
} 
Os estudantes beneficiários do Programa Bolsa Familia no contexto da educação pública do Paraná: uma leitura a partir das mesorregiões do estado

Ainda que as regiões congreguem municípios com características semelhantes, ela não é totalmente homogênea e linear, tal como por exemplo, a região metropolitana de Curitiba (RMC), que tem municípios com Índice de Desenvolvimento Humano Municipal (IDHM) de 0,63 a 0,82 e taxa de crianças pobres e extremamente pobres de 74,96, bem como de 6,28. Nesse sentido, é interessante visualizar como os beneficiários se distribuem dentro dos municípios das mesorregiões. As regiões, Centro Ocidental, Centro Oriental, Centro Sul, Norte Pioneiro e Sudeste têm mais de $50 \%$ dos seus municípios na faixa de médio alto e alto número de beneficiários nos anos iniciais do Ensino Fundamental (EF), como é possível perceber na tabela 4.

Tabela 4 - Número de municípios em cada faixa de percentual de beneficiários do PBF nos anos iniciais do Ensino Fundamental, Paraná, 2015.

\begin{tabular}{|c|c|c|c|c|c|c|c|c|c|}
\hline & \multicolumn{2}{|c|}{ Baixo } & \multicolumn{2}{|c|}{ Médio Baixo } & \multicolumn{2}{|c|}{ Médio Alto } & \multicolumn{2}{|c|}{ Alto } & \multirow{2}{*}{$\frac{\text { Total }}{\mathrm{N}^{\circ}}$} \\
\hline & $\mathrm{N}^{\circ}$ & $\%$ & $\mathrm{~N}^{\circ}$ & $\%$ & $\mathrm{~N}^{\circ}$ & $\%$ & $\mathrm{~N}^{\circ}$ & $\%$ & \\
\hline Centro Ocidental & 1 & 4,0 & 2 & 8,0 & 10 & 40,0 & 12 & 48,0 & 25 \\
\hline Centro Oriental & 2 & 14,3 & 3 & 21,4 & 6 & 42,9 & 3 & 21,4 & 14 \\
\hline Centro Sul & 0 & 0,0 & 2 & 6,9 & 10 & 34,5 & 17 & 58,6 & 29 \\
\hline Metropolitana & 12 & 32,4 & 11 & 29,7 & 9 & 24,3 & 5 & 13,5 & 37 \\
\hline Noroeste & 24 & 39,3 & 17 & 27,9 & 10 & 16,4 & 10 & 16,4 & 61 \\
\hline Norte Central & 25 & 31,6 & 20 & 25,3 & 19 & 24,1 & 15 & 19,0 & 79 \\
\hline Norte Pioneiro & 1 & 2,2 & 10 & 21,7 & 10 & 21,7 & 25 & 54,3 & 46 \\
\hline Oeste & 22 & 44,0 & 13 & 26,0 & 9 & 18,0 & 6 & 12,0 & 50 \\
\hline Sudeste & 4 & 19,0 & 6 & 28,6 & 8 & 38,1 & 3 & 14,3 & 21 \\
\hline Sudoeste & 8 & 21,6 & 16 & 43,2 & 10 & 27,0 & 3 & 8,1 & 37 \\
\hline
\end{tabular}

Fonte: Banco de dados do Sistema Presença (2015); Microdados do Censo Escolar (2015).

A região Centro Sul é a que concentra o maior número de municípios nas faixas médio alto e alta, chegando a 93,1\%, seguido do Centro Ocidental com $88 \%$ e do Norte Pioneiro com $76 \%$ dos seus municípios com um alto perfil de beneficiários. Em um estudo sobre a nova dinâmica dos municípios paranaenses, Costa e Rocha (2014) dividem os municípios em quatro categorias: fortemente dinâmicos, dinâmicos, intermediários e periféricos. Tal classificação é feita com base em diversos indicadores, como influência das cidades, relevância econômica, desempenho municipal ${ }^{4}$, taxa de pobreza e crescimento demográfico. Segundo os autores, os municípios classificados como periféricos encontram-se principalmente no Centro Sul e no Centro Ocidental, justamente onde há um maior número de municípios com alto número de beneficiários.

\footnotetext{
${ }^{4}$ A análise do desempenho municipal do Índice de Desempenho Municipal elaborado pelo Instituto Paranaense de Desenvolvimento Econômico e Social (IPARDES). Tal índice analisa a gestão municipal a partir de 3 indicadores: renda, emprego e agropecuária, saúde e educação.
} 
A região Metropolitana, Noroeste e Norte Central têm mais de $50 \%$ dos municípios com percentual baixo e médio baixo de estudantes beneficiários, sendo que essas regiões contam com polos importantes que acabam influenciando econômica e socialmente os municípios mais próximos. Dentre esses polos, destaca-se a cidade de Curitiba, São José dos Pinhais, Araucária (Metropolitana de Curitiba), Londrina e Maringá (Norte Central Paranaense). Segundo Costa e Rocha (2014, p. 97) esses podem ser considerados como Fortemente Dinâmicos e

Exercem elevada influência na rede urbana paranaense e são os principais centros industriais, comerciais e de prestação de serviços. Apresentam elevada relevância econômica contribuindo ativamente para a composição do PIB e possuem significativo crescimento populacional atuando como áreas de atração. A baixa taxa de pobreza e o elevado IPDM, indicam melhor condição de vida para a população.

Cabe ressaltar que as análises feitas no que se refere à distribuição do percentual de beneficiários nos diversos municípios das mesorregiões paranaenses para os anos inicias do EF são muito semelhantes ao que se observa nos anos finais, mantendo-se o Centro Sul, Centro Ocidental e Centro Oriental com o maior percentual de municípios com alto número de beneficiário, com destaque para o Centro Sul com 97\%. E novamente com o maior número de cidades com baixo número de estudantes do PBF, estão as mesorregiões Noroeste com 78,4\%, seguida pelo Norte Central com 64,5 e a Metropolitana com 59,4\%.

As constatações acima indicam que uma das metas em relação às ações empreendidas pelo Estado brasileiro, mais fortemente desde 2003 até meados de 2016, parece estar sendo cumprida, qual seja de 'encontrar' a população mais pobre e fazer com que os benefícios sociais pudessem alcançar aqueles que dela mais precisam e que, por vezes, devido ao seu nível de exclusão, desinformação não logram exigir ou mesmo usufruir dos seus direitos (CAMPELLO; MELLO, 2014).

A proporcionalidade maior ou menor de beneficiários nas diversas mesorregiões é compatível com a maior ou menor renda domiciliar per capita do quintil mais pobre da população da região, há uma tendência de que, quanto maior for a renda, menor é o percentual de beneficiários do Programa Bolsa Família, como se constata na tabela abaixo. 
Os estudantes beneficiários do Programa Bolsa Familia no contexto da educação pública do Paraná: uma leitura a partir das mesorregiões do estado

Tabela 5a - Média da renda domiciliar (em reais) per capita máxima do quinto mais pobre nas mesorregiões segundo a faixa de beneficiários do programa bolsa família nos anos iniciais do EF, Paraná, 2015.

\begin{tabular}{ccccc}
\hline \% de beneficiários & Baixo & Médio Baixo & Médio Alto & Alto \\
\hline Centro Ocidental & 325 & 215 & 213 & 184 \\
\hline Centro Oriental & 216 & 213 & 172 & 142 \\
Centro Sul & - & 136 & 143 & 123 \\
Metropolita & 290 & 214 & 160 & 166 \\
Noroeste & 279 & 243 & 238 & 212 \\
Norte Central & 281 & 279 & 223 & 211 \\
Norte Pioneiro & 251 & 219 & 208 & 197 \\
Oeste & 289 & 235 & 188 & 164 \\
Sul & 201 & 153 & 158 & 145 \\
Sudoeste & 245 & 229 & 190 & 202 \\
\hline
\end{tabular}

Fonte: Banco de dados do Sistema Presença (2015); Atlas do Desenvolvimento Humano Municipal (2010).

A região Centro Oriental é a que possui a menor média de renda da população mais pobre, o que é explicável, haja vista que essa é uma das mesorregiões mais pobres do Paraná, mais de um terço da população do Centro Sul é considerada pobre (INSTITUTO PARANAENSE DE DESENVOLVIMENTO ECONÔMICO E SOCIAL [IPARDES], 2004) sendo também uma das regiões com o maior percentual de beneficiários. Os 29 municípios pertencentes a essa região, em geral, têm baixa densidade demográfica e pouco grau de urbanização.

Cabe ainda destacar que a composição social dessa mesorregião tem uma característica particular, por incorporar, com maior intensidade, dois segmentos sociais que realizam trajetórias marcadas pelas dificuldades de superação da pobreza. Nessa mesorregião estão concentradas $61,7 \%$ das áreas indígenas e 41,7\% das áreas de assentamento do Estado. (IPARDES, 2004, p. 37).

Contudo há grandes discrepâncias presentes nos municípios das mesmas mesorregiões, com diferenças na média de renda que chega a 141 reais na região Metropolitana de Curitiba. O Sudoeste, por sua vez, difere-se um pouco das demais mesorregiões, haja vista que a média da renda dos municípios com elevada número de estudantes do PBF é superior à renda daqueles classificados como médio alto, o que sinaliza que, apesar de mais amplamente o Programa Bolsa Família conseguir chegar à parcela mais necessitada da população, isso não ocorre de forma homogênea em todo o Estado. Tal situação pode estar relacionada com o fato de que essa é a região do Estado com a menor taxa de urbanização, sendo que, em alguns municípios dessa mesorregião, a taxa de frequência ao ensino fundamental 
é inferior à média do Estado, impedindo, portanto, o acesso ao beneficio concedido pelo programa.

É interessante observar que, nos anos finais do Ensino Fundamental, a relação entre o acesso ao programa e as piores condições é ainda mais presente, como se constata na tabela abaixo.

Tabela $5 \mathrm{~b}$ - Média da renda domiciliar (em reais) per capita máxima do quinto mais pobre nas mesorregiões segundo a faixa de beneficiários do programa bolsa família nos anos finais do EF, Paraná, 2015.

\begin{tabular}{|ccccc}
\hline \% de beneficiários & Baixo & Médio Baixo & Médio Alto & Alto \\
\hline Centro Ocidental & 261 & 241 & 199 & 160 \\
Centro Oriental & 222 & 223 & 168 & 153 \\
Centro Sul & & 177 & 169 & 120 \\
Metropolita & 291 & 222 & 179 & 143 \\
Noroeste & 279 & 237 & 233 & 205 \\
Norte Central & 299 & 256 & 241 & 166 \\
Norte Pioneiro & & & & \\
Oeste & 213 & 227 & 203 & 185 \\
Sul & 296 & 242 & 188 & 155 \\
\hline Sudoeste & 238 & 184 & 176 & 140 \\
\hline
\end{tabular}

Fonte: Banco de dados do Sistema Presença (2015); Atlas do Desenvolvimento Humano Municipal (2010).

Ao analisar outros indicadores como a taxa de pobreza, perspectiva de anos de estudo, taxa de analfabetismo nas diversas mesorregiões, verifica-se que o atendimento chega, em geral, aos estudantes que vivem em condições mais precárias, ou cujos municípios apresentam indicadores, sociais, econômicos e mesmo educacionais inferiores, como se constata na tabela 6 . No caso dos dois indicadores educacionais, é interessante observar que, quando se trata da expectativa de anos de estudo aos 18 anos de idade, em todas as faixas a média é parecida, o que pode se relacionar com a obrigatoriedade da educação dos 4 aos 17 anos, porém, em nenhum caso, a expectativa é de cumprimento dos 13 anos obrigatórios. No caso da taxa de analfabetismo, o crescimento desse indicador na faixa de alto número de beneficiários reforça a perspectiva que a pobreza não é medida apenas pela renda diretamente. 
TABELA 6 - Indicadores sociais segundo a faixa de beneficiários do PBF nos anos iniciais do EF, Paraná, 2015.

\begin{tabular}{ccccc}
\hline & Baixo & Médio Baixo & Médio Alto & Alto \\
\hline Expectativa de anos de estudo aos 18 anos & 10,65 & 10,65 & 10,34 & 10,37 \\
Taxa de analfabetismo pop de 15 anos ou mais & 8,08 & 9,04 & 11,19 & 13,16 \\
Proporção de crianças extremamente pobres & 2,56 & 4,54 & 6,83 & 7,66 \\
Taxa de atividade das pessoas de 10 a 14 anos & 11,09 & 11,58 & 13,25 & 13,95 \\
$\begin{array}{c}\text { \% da população que vive em domicílios com } \\
\text { água encanada }\end{array}$ & 95,25 & 93,26 & 91,5 & 91,66 \\
$\begin{array}{c}\text { \% da população que vive em domicílios com } \\
\text { energia elétrica }\end{array}$ & 99,72 & 99,38 & 99,04 & 98,93 \\
\hline
\end{tabular}

Fonte: Banco de dados do Sistema Presença (2015); Atlas do Desenvolvimento Humano Municipal (2010).

As análises apresentadas acima dão indicativos mais gerais do alcance do PBF no Estado do Paraná, entretanto entende-se que, para além da análise mais global, é necessário que se observe o quanto esse acesso à renda possibilita ou se converte em capacidades de acesso a outros bens sociais, nesse caso especificamente à educação. A análise centra o olhar nas escolas em que estão os beneficiários, analisando o quanto as condições dessas escolas, em termos de qualificação ou vínculo docente, ou mesmo de materiais e espaços pedagógicos, têm relação com as próprias condições sociais dos educandos.

\section{AS CONDIÇÕES DE QUALIDADE DAS ESCOLAS NAS MESORREGIÕES DO PARANÁ}

Para discutir as condições de oferta educacional considerando a inserção dos estudantes pobres nas escolas nas mesorregiões paranaenses, cabe primeiro observar a distribuição desses estudantes beneficiários do PBF no estado. Tomam-se inicialmente as condições das redes municipais, portanto os dados de oferta dos anos iniciais do ensino fundamental. A tabela 7a apresenta o número de escolas em cada mesorregião que consta no banco de dados da pesquisa considerando o percentual de escolas por faixa de estudantes beneficiários. 
Tabela 7a - Número de escolas por mesorregião de acordo com o percentual de estudantes beneficiários do PBF nos anos iniciais do Ensino Fundamental, Paraná, 2015.

\begin{tabular}{|c|c|c|c|c|c|c|c|c|c|c|}
\hline \multirow[t]{3}{*}{ Mesorregiões } & \multicolumn{10}{|c|}{ Faixa de beneficiários por escola (quartis) } \\
\hline & \multicolumn{2}{|c|}{$\begin{array}{c}\text { Baixa } \\
\text { (até } 11 \%)\end{array}$} & \multicolumn{2}{|c|}{$\begin{array}{l}\text { Média Baixa } \\
(11 \% \text { a } 19 \%)\end{array}$} & \multirow{2}{*}{$\begin{array}{c}\text { Até } \\
19 \% \\
\%\end{array}$} & \multicolumn{2}{|c|}{$\begin{array}{c}\text { Média Alta } \\
(19 \% \text { a } 31 \%)\end{array}$} & \multicolumn{2}{|c|}{$\begin{array}{c}\text { Alta } \\
\text { (mais 31\%) }\end{array}$} & \multirow{2}{*}{$\begin{array}{c}\text { Mais de } \\
19 \% \\
\%\end{array}$} \\
\hline & $\mathrm{N}$ & $\%$ & $\mathrm{~N}$ & $\%$ & & $\mathrm{~N}$ & $\%$ & $\mathrm{~N}$ & $\%$ & \\
\hline Centro Sul & 30 & 11,8 & 53 & 20,8 & 32,5 & 107 & 42,0 & 65 & 25,5 & 67,5 \\
\hline Centro Ocidental & 16 & 14,5 & 23 & 20,9 & 35,5 & 46 & 41,8 & 25 & 22,7 & 64,5 \\
\hline Norte Pioneiro & 27 & 14,0 & 53 & 27,5 & 41,5 & 64 & 33,2 & 49 & 25,4 & 58,5 \\
\hline Sudeste & 64 & 29,8 & 76 & 35,3 & 65,1 & 54 & 25,1 & 21 & 9,8 & 34,9 \\
\hline Sudoeste & 68 & 33,2 & 67 & 32,7 & 65,9 & 56 & 27,3 & 14 & 6,8 & 34,1 \\
\hline Centro Oriental & 77 & 32,4 & 89 & 37,4 & 69,7 & 50 & 21,0 & 22 & 9,2 & 30,3 \\
\hline Noroeste & 67 & 37,4 & 61 & 34,1 & 71,5 & 42 & 23,5 & 9 & 5,0 & 28,5 \\
\hline Norte Central & 173 & 37,9 & 158 & 34,6 & 72,6 & 103 & 22,6 & 22 & 4,8 & 27,4 \\
\hline Oeste & 170 & 47,4 & 114 & 31,8 & 79,1 & 61 & 17,0 & 14 & 3,9 & 20,9 \\
\hline Metropolitana & 333 & 44,5 & 267 & 35,6 & 80,1 & 119 & 15,9 & 30 & 4,0 & 19,9 \\
\hline
\end{tabular}

Fonte: Banco de dados do Sistema Presença (2015); Microdados do Censo Escolar (2015).

As mesorregiões Centro Sul, Centro Ocidental e Norte Pioneiro concentram um número expressivo de escolas que têm média alta e alta participação dos estudantes pobres na matrícula. As regiões Metropolitana, Oeste, Norte Central e Noroeste apresentam o maior percentual de escolas com baixa e média baixa proporção de estudantes do PBF.

Quando se observa a mesma distribuição nos anos finais, em que predomina a oferta da dependência administrativa estadual, verifica-se que as mesorregiões com maior número de beneficiários nas escolas segue quase a mesma tendência dos anos iniciais. O Centro Sul e Centro Ocidental concentram escolas com um percentual bastante alto de beneficiários do PBF, a mesorregião metropolitana e o noroeste têm um número maior de escolas nos menores percentuais de estudantes beneficiários do PBF, assim como nos anos iniciais. 
Os estudantes beneficiários do Programa Bolsa Familia no contexto da educação pública do Paraná: uma leitura a partir das mesorregiões do estado

Tabela $7 \mathrm{~b}$ - Número de escolas por mesorregião de acordo com o percentual de estudantes beneficiários do PBF nos anos finais do Ensino Fundamental, Paraná, 2015.

\begin{tabular}{|c|c|c|c|c|c|c|c|c|c|c|}
\hline \multirow[t]{3}{*}{ Mesorregiões } & \multicolumn{10}{|c|}{ Faixa de beneficiários por escola (quartis) } \\
\hline & \multicolumn{2}{|c|}{$\begin{array}{c}\text { Baixa } \\
\text { (até } 11 \%)\end{array}$} & \multicolumn{2}{|c|}{$\begin{array}{l}\text { Média Baixa } \\
(11 \% \text { a } 19 \%)\end{array}$} & \multirow{2}{*}{$\begin{array}{c}\text { Até } \\
19 \% \\
\%\end{array}$} & \multicolumn{2}{|c|}{$\begin{array}{c}\text { Média Alta } \\
\text { (19\% a } 31 \%)\end{array}$} & \multicolumn{2}{|c|}{$\begin{array}{c}\text { Alta } \\
\text { (mais } 31 \%)\end{array}$} & \multirow{2}{*}{$\begin{array}{c}\text { Mais de } \\
19 \% \\
\%\end{array}$} \\
\hline & $\mathrm{N}$ & $\%$ & $\mathrm{~N}$ & $\%$ & & $\mathrm{~N}$ & $\%$ & $\mathrm{~N}$ & $\%$ & \\
\hline Metropolitana & 57 & 13,6 & 102 & 24,3 & 37,9 & 132 & 31,4 & 129 & 30,7 & 62,1 \\
\hline Noroeste & 16 & 11,7 & 29 & 21,2 & 32,8 & 51 & 37,2 & 41 & 29,9 & 67,2 \\
\hline Oeste & 32 & 12,5 & 48 & 18,8 & 31,4 & 79 & 31,0 & 96 & 37,6 & 68,6 \\
\hline Norte Central & 23 & 7,5 & 67 & 22,0 & 29,5 & 98 & 32,1 & 117 & 38,4 & 70,5 \\
\hline Sudoeste & 6 & 3,8 & 16 & 10,1 & 13,9 & 34 & 21,5 & 102 & 64,6 & 86,1 \\
\hline Centro Oriental & 5 & 3,5 & 9 & 6,3 & 9,9 & 37 & 26,1 & 91 & 64,1 & 90,1 \\
\hline Norte Pioneiro & 2 & 1,4 & 10 & 6,8 & 8,1 & 27 & 18,2 & 109 & 73,6 & 91,9 \\
\hline Sudeste & 1 & 0,9 & 5 & 4,7 & 5,7 & 16 & 15,1 & 84 & 79,2 & 94,3 \\
\hline Centro Ocidental & 0 & 0,0 & 4 & 4,9 & 4,9 & 14 & 17,3 & 63 & 77,8 & 95,1 \\
\hline Centro Sul & 1 & 0,6 & 2 & 1,3 & 1,9 & 3 & 1,9 & 153 & 96,2 & 98,1 \\
\hline
\end{tabular}

Fonte: Banco de dados do Sistema Presença (2015); Microdados do Censo Escolar (2015).

Considerar condições de qualidade de oferta igualitárias implicaria ter tendencialmente os mesmos indicadores de oferta em todas as mesorregiões. Observe-se o que acontece inicialmente com o perfil dos professores no ensino fundamental nas escolas por mesorregião.

Como primeiro elemento básico para considerar as condições de trabalho, destaca-se a questão do vínculo empregatício. As redes municipais apresentam um percentual de professores efetivos tendencialmente maior que os das redes estaduais, segundo dados do INEP (2016), no Paraná, no conjunto das redes municipais 93\% dos professores são concursados, sendo que, na rede Estadual, esse percentual decresce para 73\% no que se refere ao Ensino Fundamental em 2015. Ao observar as condições de vínculos nos anos iniciais no Paraná em que predominam as redes municipais como dependência administrativa, observa-se que os vínculos estatutários superam $80 \%$ das redes em todas as regiões.

A correlação de Pearson entre o percentual de beneficiários do PBF e vínculo do professor é baixa $(-1,49)$, porém é estatisticamente significativa e é negativa, ou seja, quando se amplia o número de beneficiários matriculados na escola, diminui o número de professores estatutários. Ao observar a distribuição de professores estatutários considerando as faixas de participação dos estudantes do PBF, pode-se perceber que o percentual médio de professores estatutários é menor que 80\% na região Centro Sul e, apenas na faixa com alta percentagem de estudantes beneficiários do PBF e na região sudeste, na faixa média baixa. Ainda que, com variação, parece que este é um indicador que tende a ser mais favorável no conjunto das redes municipais. 
Tabela 8a - Percentual de professores com vínculo estatutário em escolas dos anos iniciais do Ensino Fundamental por mesorregião e faixa de participação de beneficiários do PBF, Paraná, 2015.

\begin{tabular}{cccccc}
\hline Mesorregiões & Total & \multicolumn{4}{c}{ Faixa de beneficiários por escola (quartis) } \\
\cline { 2 - 5 } & Média & Baixa & Média Baixa & Média Alta & Alta \\
Sudoeste & 82,43 & 82,70 & 79,81 & 85,32 & 82,00 \\
Centro Sul & 82,53 & 84,51 & 89,66 & 83,04 & 75,94 \\
Norte Pioneiro & 85,61 & 83,97 & 85,36 & 82,87 & 90,40 \\
Oeste & 87,27 & 87,66 & 89,60 & 81,83 & 87,40 \\
Centro Ocidental & 91,79 & 96,53 & 93,21 & 89,03 & 93,04 \\
Centro Oriental & 92,49 & 95,13 & 92,61 & 89,77 & 89,62 \\
Norte Central & 92,73 & 94,01 & 92,46 & 91,31 & 91,35 \\
Sudeste & 92,75 & 91,29 & 91,53 & 95,37 & 92,97 \\
Noroeste & 93,33 & 94,70 & 90,98 & 95,41 & 90,15 \\
Metropolitana & 93,35 & 95,72 & 93,98 & 88,94 & 80,38 \\
\hline
\end{tabular}

Fonte: Banco de dados do Sistema Presença (2015); Microdados do Censo Escolar (2015).

Cabe considerar que a média de professores estatutário é menor no Sudoeste e no Centro Sul, justamente as mesorregiões que concentram o maior número de beneficiários e que apresentam condições sociais e econômicas piores quando comparadas ao restante do Estado.

Observar essa mesma condição nas escolas com oferta de anos finais do ensino fundamental e que são predominantemente de responsabilidade da rede estadual de ensino do Paraná, revela um quadro mais preocupante. A correlação de Pearson entre a variável percentual de beneficiários do PBF e percentual de professores estatutários neste caso é de-0,329, novamente é negativa indicando que, quando cresce a presença de estudantes pobres, diminui a presença de professores estatutários, mas também é evidente o aumento de outros tipos de vínculos.

A média geral, nesse caso, de professores estatutários, não ultrapassa 80\% em nenhuma mesorregião. É bastante acentuada a diferença entre o percentual e professores estatutários atuando em escolas que têm ate $11 \%$ de estudantes do PBF e naquelas que têm mais de $31 \%$. Parece que a questão do vínculo constante à rede de ensino na forma de concurso é um problema geral na rede estadual, porém ele não tem uma distribuição igualitária quando se considera o perfil de renda dos estudantes, o que parece impor um cenário de dupla desigualdade de condições de oferta. 
Os estudantes beneficiários do Programa Bolsa Familia no contexto da educação pública do Paraná: uma leitura a partir das mesorregiões do estado

Tabela $8 \mathrm{~b}$ - Percentual de professores com vínculo estatutário em escolas dos anos iniciais do Ensino Fundamental por mesorregião e faixa de participação de beneficiários do PBF, Paraná, 2015.

\begin{tabular}{cccccc}
\hline Mesorregiões & Total & \multicolumn{4}{c}{ Faixa de beneficiários por escola (quartis) } \\
\cline { 2 - 6 } Centro Sul & Média & Baixa & Média Baixa & Média Alta & Alta \\
Centro Oriental & 54,61 & 96,30 & 67,38 & 85,51 & 53,57 \\
Sudoeste & 59,71 & 88,03 & 73,21 & 72,07 & 51,79 \\
Sudeste & 65,45 & 75,87 & 74,70 & 66,18 & 63,15 \\
Noroeste & 65,79 & 70,73 & 67,64 & 75,38 & 63,79 \\
Oeste & 66,39 & 71,28 & 68,99 & 65,36 & 63,94 \\
Metropolitana & 67,32 & 73,63 & 67,47 & 71,19 & 61,96 \\
Centro Ocidental & 67,85 & 80,97 & 73,97 & 67,39 & 57,67 \\
Norte Pioneiro & 69,96 & & 77,96 & 71,01 & 69,22 \\
Norte Central & 73,04 & 70,83 & 80,77 & 78,93 & 70,92 \\
\hline
\end{tabular}

Fonte: Banco de dados do Sistema Presença (2015); Microdados do Censo Escolar (2015).

Além da questão do vínculo de trabalho, outra dimensão possível de ser observada são as condições de formação inicial dos professores. Ainda que a Lei de Diretrizes e Bases da Educação Nacional- LDB 9.394/1996 (BRASIL, 1996) faça uma diferenciação entre a formação mínima admitida para atuação nos anos iniciais e finais do ensino fundamental, a formação em licenciatura é aquela definida como meta. Assim, toma-se como condição de qualidade da oferta a presença de professores com formação de nível superior em licenciatura no conjunto das escolas. Para dimensionar um elemento de ampliação da formação, consideraremos a meta do Plano Nacional de Educação (PNE) que estabelece a perspectiva de formação de pelo menos $50 \%$ dos professores da educação básica em cursos de pós-graduação, o PNE não estabelece em que modalidade stricto ou lato sensu, assim, optou-se aqui por considerar aquela que é mais comum nas redes, ou seja, a formação lato sensu em cursos de especialização.

No caso das escolas com oferta de anos iniciais do ensino fundamental observe que a mesorregião Centro Sul apresenta o menor percentual de professores com licenciatura $(66,07 \%)$ e este aparece nas escolas em que há alto percentual de beneficiários do PBF. As mesorregiões Sudoeste, Centro oriental, Norte pioneiro e Sudeste apresentam em todas as faixas de beneficiários mais de $80 \%$ de professores com licenciatura. As regiões Metropolitana, Oeste e Noroeste parecem conter mais desigualdades de oferta neste quesito, pois, nas faixas com menor número de estudantes do PBF, a formação em licenciatura ultrapassa os 90\% enquanto, nas faixas com mais estudantes do PBF, a proporção dos professores licenciados também 
diminui. Aqui cabe considerar que estamos tratando de forma agregada professores que trabalham em diferentes municípios, portanto com diferentes planos de carreira e exigências de formação para entrada nas redes.

Tabela 9a - Percentual de professores com formação em licenciatura em escolas dos anos iniciais do Ensino Fundamental, por mesorregião e faixa de participação de beneficiários do PBF, Paraná, 2015.

\begin{tabular}{ccccc}
\hline Mesorregiões & \multicolumn{3}{c}{ Faixa de beneficiários por escola (quartis) } \\
\cline { 2 - 5 } & Baixa & Média Baixa & Média Alta & Alta \\
Centro Sul & 84,47 & 84,69 & 79,35 & 66,07 \\
Metropolitana & 92,24 & 88,03 & 80,04 & 73,98 \\
Oeste & 90,43 & 87,54 & 82,65 & 82,21 \\
Sudoeste & 86,70 & 83,34 & 85,43 & 85,01 \\
Centro Oriental & 88,08 & 83,97 & 82,15 & 85,69 \\
Norte Pioneiro & 87,61 & 88,43 & 80,93 & 86,03 \\
Noroeste & 93,99 & 91,26 & 90,35 & 87,02 \\
Sudeste & 81,79 & 85,91 & 86,73 & 88,78 \\
Centro Ocidental & 94,31 & 91,74 & 91,09 & 90,57 \\
Norte Central & 94,46 & 91,09 & 90,05 & 92,23 \\
\hline
\end{tabular}

Fonte: Banco de dados do Sistema Presença (2015); Microdados do Censo Escolar (2015).

Nessas mesmas redes, considerar a formação em especialização para os professores dos anos iniciais do ensino fundamental revela um quadro de mais desigualdade de oferta em desfavor às escolas com maior número de estudantes beneficiários do PBF, especialmente nas regiões Metropolitana e Centro Sul. Chama a atenção esse indicador na mesorregião Noroeste, em que todas as escolas têm mais que $80 \%$ dos professores com formação em especialização.

Tabela $9 \mathrm{~b}$ - Percentual de professores com especialização em escolas dos anos finais do Ensino Fundamental, por mesorregião e faixa de participação de beneficiários do PBF, Paraná, 2015.

\begin{tabular}{ccccc}
\hline Mesorregiões & \multicolumn{4}{c}{ Faixa de beneficiários por escola (quartis) } \\
\hline Metropolitana & 51,25 & Média Baixa & Média Alta & Alta \\
Centro Sul & 52,47 & 69,39 & 42,31 & 32,29 \\
Centro Ocidental & 74,22 & 69,36 & 63,47 & 50,93 \\
Sudeste & 64,96 & 69,68 & 75,35 & 65,35 \\
Oeste & 76,34 & 71,61 & 71,22 & 67,04 \\
Centro Oriental & 63,08 & 57,62 & 69,61 & 67,28 \\
Norte Pioneiro & 70,47 & 72,48 & 64,53 & 69,45 \\
Sudoeste & 77,32 & 73,04 & 66,13 & 69,68 \\
Norte Central & 81,69 & 76,55 & 74,14 & 72,89 \\
Noroeste & 85,16 & 84,17 & 76,42 & 77,38 \\
\hline
\end{tabular}

Fonte: Banco de dados do Sistema Presença (2015); Microdados do Censo Escolar (2015). 
Os estudantes beneficiários do Programa Bolsa Familia no contexto da educação pública do Paraná: uma leitura a partir das mesorregiões do estado

No caso dos anos finais do ensino fundamental, o predomínio da oferta pela rede estadual de ensino significa plano de carreira e condições de ingresso, para o caso dos professores temporários, mais uniforme. Portanto espera-se uma menor desigualdade de padrão de formação. A tabela 7 confirma essa expectativa evidenciando que, na maior parte das regiões, mais de 95\% dos professores têm licenciatura para atuar nos anos finais do ensino fundamental. Destaca-se, entretanto, que, quando há menos de $95 \%$ dos professores com licenciatura, isto ocorre em escolas com mais de $19 \%$ de estudantes beneficiários do programa bolsa família. A mesma tendência se coloca no caso da formação em especialização, entretanto, nesse quesito, chama a atenção o percentual de professores com especialização na mesorregião Metropolitana que, em todas as faixas de beneficiários do PBF, é a menor encontrada.

Tabela 10 - Percentual de professores por tipo de formação em escolas dos anos finais do Ensino Fundamental, por mesorregião e faixa de participação de beneficiários do PBF, Paraná, 2015.

\begin{tabular}{|c|c|c|c|c|c|c|c|c|}
\hline \multirow{3}{*}{$\begin{array}{c}\text { Formação } \\
\text { Mesoregiões }\end{array}$} & \multicolumn{4}{|c|}{ Licenciatura } & \multicolumn{4}{|c|}{ Especialização } \\
\hline & \multicolumn{4}{|c|}{ Faixa de beneficiários por escola (quartis) } & \multicolumn{4}{|c|}{$\begin{array}{l}\text { Faixa de beneficiários por escola } \\
\text { (quartis) }\end{array}$} \\
\hline & Baixa & Média Baixa & $\begin{array}{l}\text { Média } \\
\text { Alta }\end{array}$ & Alta & Baixa & $\begin{array}{l}\text { Média } \\
\text { Baixa }\end{array}$ & $\begin{array}{l}\text { Média } \\
\text { Alta }\end{array}$ & Alta \\
\hline Centro Ocidental & & 99,49 & 98,56 & 98,12 & & 97,36 & 96,31 & 94,47 \\
\hline Centro Oriental & 97,26 & 97,29 & 96,97 & 93,89 & 84,79 & 87,19 & 83,24 & 84,09 \\
\hline Centro Sul & 96,30 & 100,00 & 100,00 & 93,31 & 92,59 & 92,45 & 90,88 & 85,48 \\
\hline Metropolitana & 96,65 & 95,02 & 93,95 & 90,00 & 80,32 & 75,39 & 73,01 & 67,68 \\
\hline Noroeste & 96,95 & 97,94 & 97,02 & 97,65 & 94,93 & 93,88 & 95,46 & 93,74 \\
\hline Norte Central & 97,45 & 98,38 & 98,15 & 97,55 & 91,10 & 91,60 & 90,37 & 93,04 \\
\hline Norte Pioneiro & 94,07 & 97,63 & 97,14 & 96,83 & 85,86 & 95,84 & 94,21 & 92,87 \\
\hline Oeste & 98,60 & 97,02 & 97,22 & 95,78 & 92,99 & 89,82 & 92,70 & 89,85 \\
\hline Sudeste & 100,00 & 99,57 & 98,47 & 96,63 & 90,24 & 92,66 & 89,13 & 86,40 \\
\hline Sudoeste & 99,54 & 97,40 & 97,37 & 94,97 & 95,88 & 92,49 & 93,28 & 89,68 \\
\hline
\end{tabular}

Fonte: Banco de dados do Sistema Presença (2015); Microdados do Censo Escolar (2015).

Outro elemento a se considerar quando se analisam condições das escolas refere à existência ou não de espaços pedagógico, infraestrutura etc. Aqui optamos por analisar especificamente a questão do laboratório de informática. Nessa análise, o que se percebe é que há uma tendência de que as melhores condições estejam localizadas nas escolas das mesorregiões que possuem um número menor de beneficiários, contudo, para as escolas de anos iniciais, ela não se aplica ao Centro Sul, Centro Oriental e Norte Pioneiro, o que pode estar relacionado ao fato de essas regiões, terem um baixo número de beneficiários em escolas rurais. No Centro Ocidental, 31,3\% das escolas com baixo número de alunos no PBF são rurais, sendo 
que, no outro extremo, na faixa alta, esse número cai para 20\%; no Centro Sul, esse percentual é de 73 caindo para 47; no Norte Pioneiro, tem-se 29\% das escolas rurais que têm poucos alunos do PBF, contra $26 \%$ com alto número de alunos, no qual a diferença entre as médias não é tão alta, como se pode perceber na tabela abaixo.

Tabela 11 - Média das escolas de anos inicias e anos finais com laboratório de informática por mesorregião e faixa de participação de beneficiários do PBF, Paraná, 2015.

\begin{tabular}{ccccccccc}
\hline & \multicolumn{3}{c}{ ANOS INICIAIS DO EF } & \multicolumn{5}{c}{ ANOS FINAIS DO EF } \\
\hline & Baixo & Médio Baixo & Médio Alto & Alto & Baixo & Médio Baixo & Médio Alto & Alto \\
C. Ocidental & 68,8 & 82,6 & 71,7 & 76,0 & & 100 & 78,6 & 93,7 \\
C. Oriental & 83,1 & 71,9 & 62,0 & 50,0 & 100 & 77,8 & 94,6 & 86,8 \\
Centro Sul & 53,3 & 67,9 & 78,5 & 76,9 & 100 & 100 & 66,7 & 85,6 \\
Metropolitana & 78,1 & 69,3 & 58,0 & 43,3 & 98,2 & 96,1 & 96,2 & 92,2 \\
Noroeste & 76,1 & 78,7 & 73,8 & 77,8 & 93,8 & 93,1 & 98,0 & 97,6 \\
Norte Central & 72,8 & 74,1 & 66,0 & 68,2 & 91,3 & 94,0 & 93,9 & 94,9 \\
Norte & 55,6 & 66,0 & 64,1 & 59,2 & 100 & 90,0 & 92,6 & 90,8 \\
Pioneiro & & & & & & & & \\
Oeste & 91,8 & 93,0 & 86,9 & 85,7 & 100 & 91,7 & 93,7 & 90,6 \\
Sudeste & 42,2 & 72,4 & 61,1 & 61,9 & 100 & 80,0 & 81,3 & 89,3 \\
Sudoeste & 76,5 & 85,1 & 71,4 & 64,3 & 100 & 100 & 94,1 & 95,1 \\
\hline
\end{tabular}

Fonte: Banco de dados do Sistema Presença (2015); Microdados do Censo Escolar (2015).

A literatura da área de política educacional tem evidências de que as condições das escolas na zona rural têm sido mais precárias (SCHNEIDER, 2010), o que pode ajudar a explicar as médias mais baixas das escolas com baixo número de beneficiários em algumas mesorregiões. No caso dos anos finais, o número de escolas rurais em geral é menor, e não auxilia a explicar a média mais baixa das duas regiões, uma análise mais detalhada dos municípios que compõem essas mesorregiões seria mais elucidativa, porém não é escopo deste trabalho.

Ainda que as tendências não sejam as mesmas em todas as regiões, porque outros fatores interferem nas definições e nos desdobramentos das políticas, não se pode ignorar o fato de que, na maioria das escolas com baixo número de alunos do programa, a presença de laboratório de informática seja maior do que nas com alto número; tal tendência se repete para outras variáveis de condições de oferta como existência de biblioteca, internet, laboratório de ciências, com algumas diferenças em algumas regiões.

Ao analisar as escolas sem o recorte das mesorregiões, tal tendência fica mais explícita, contudo, no âmbito das regiões, ela se difere, indicando que existem outros elementos que interferem na relação entre educação e pobreza. Estes podem estar relacionados à questão de localização da escola, ao tamanho do município e 
Os estudantes beneficiários do Programa Bolsa Família no contexto da educação pública do Paraná: uma leitura a partir das mesorregiões do estado

consequentemente ao número de escolas sobre sua responsabilidade, mas também podem indicar que políticas educacionais estejam sendo pensadas visando melhorar a qualidade das escolas.

\section{PARA CONTINUAR PENSANDO}

O Programa Bolsa Família, por meio da condicionalidade escolar, tem auxiliado a permanência de crianças e adolescentes na escola (FAHEL; FRANÇA; MORAES, 2011), mas entende-se que é preciso olhar além, e analisar em que condições o cumprimento da condicionalidade da frequência à escola tem se constituído. Tal análise ajuda refletir sobre quanto a escola ainda está deixando de ser excludente no acesso, para se tornar excludente no processo, afinal o que se tem percebido nos últimos anos é

Uma ampliação para menos, a escola inclui crianças, amplia suas funções, amplia tempos e espaços, porém com prejuízo de suas funções propriamente escolares. Uma ação combinada de aligeiramento de conteúdos e sistemas de avaliação, precarização dos espaços físicos e formas de trabalho docente, [...]. (YANNOULAS, 2013, p. 45).

Uma análise mais geral da realidade paranaense sinaliza justamente para essa questão, municípios ou mesmo escolas em que há um número maior de beneficiários, há uma tendência de que as condições de oferta sejam mais precárias. Porém, ao focalizar um pouco mais essa análise, tal tendência, apesar de ainda permanecer, não é tão linear porque a ela se acrescentam elementos relacionados às condições mais gerais dos diversos municípios que compõem cada região.

Ao analisar a questão docente nas mesorregiões, com destaque para a questão do vínculo empregatício, é possível perceber que, apesar de as diferenças não serem tão grandes, em oito das dez mesorregiões há prevalência de um número maior de professores concursados nas escolas em que o número de beneficiários é menor. Há uma diferença significativa também entre a dependência administrativa da escola, sendo que, na rede municipal, o percentual de professores concursados é maior que na estadual em todas as regiões.

É necessário notar também que, no caso da rede municipal, as maiores diferenças entre o percentual de professores concursados com alto e baixo número de beneficiário encontra-se na região metropolitana de Curitiba e na região Centro Sul. Esta última é uma das mais pobres do Estado. No caso da rede estadual, isso se dá no Centro Sul e no Centro Oriental, sendo que no primeiro essa diferença chega a 42,73 pontos. 
[...] imaginar que nas periferias dos grandes centros ou nos municípios mais pobres, onde dificilmente os professores mais bem preparados estão lecionando, as escolas conseguem por si só superar suas dificuldades sem o apoio decisivo do Estado é jogar os mais pobres em um ciclo perverso de perpetuação da pobreza. (HORTA NETO, 2013, p. 131).

Tais constatações também podem ser percebidas no que se refere à formação dos professores, contudo, nesse caso, a rede municipal apresenta condição um pouco mais precária que a rede estadual, e, ainda que nem todos as mesorregiões sigam essa mesma tendência, ela ainda é presente na maior parte delas. Em relação às condições de infraestrutura a relação entre piores condições e um número maior de beneficiários, não é tão constante nas diversas mesorregiões, sendo que, nesse caso, outras variáveis precisam ser analisadas, bem como estudos mais específicos precisam ser feitos.

Essas primeiras análises indicam a necessidade de um olhar mais voltado à política educacional, com vistas a garantir que condições mais igualitárias sejam pensadas para as escolas, como mecanismos essenciais a redução da pobreza, afinal

[...] o reconhecimento de que a reforma educacional mais eficaz talvez fosse uma reforma social que modificasse a distribuição de oportunidades na sociedade não pode ser uma justificativa para a falta de ação no sentido de políticas que produzam mudanças significativas na distribuição de oportunidades educacionais. (BRUEL, 2014, p. 164).

As mudanças significativas na distribuição das oportunidades implicam, entre outras coisas, tornar a oferta escolar de fato universal com a complexidade de elementos que são necessários a uma boa escola. No caso do Paraná, as indicações aqui apresentadas permitem afirmar que as desigualdades entre as redes e dentro das redes de ensino ainda fazem o horizonte de qualidade estar distante de parte dos estudantes pobres.

\section{REFERÊNCIAS}

ATLAS BRASIL. Atlas do Desenvolvimento Humano Municipal 2010. Disponível em: <http:// www.atlasbrasil.org.br/2013/>. Acesso em: 21 mar. 2016.

BRASIL. Ministério da Educação. Lei n. 9.394 de 20 de dezembro de 1996. Lei de Diretrizes e Bases da Educação Nacional. Brasília: DF, dez. 1996.

BRUEL, A. L. Diálogos entre política educacional e sociologia: algumas reflexões sobre desigualdades sociais e educacionais. In: SILVEIRA, A. D.; GOUVEIA, A. B.; SOUZA, A. R. (Org.). Conversas sobre políticas educacionais. Curitiba: Appris, 2014. p. 143-66. 
Os estudantes beneficiários do Programa Bolsa Família no contexto da educação pública do Paraná: uma leitura a partir das mesorregiões do estado

CAMPELLO, Tereza; MELLO, Janine. O processo de formulação e os desafios do plano sem miséria: por um país rico e com oportunidades para todos. In: BRASIL. Ministério do Desenvolvimento Social e Combate à Fome. O Brasil sem miséria. Brasília: MDS, 2014. p. 33-66.

COSTA, Fábio Rodrigues da; ROCHA, Márcio Mendes. Nova dinâmica dos municípios do Paraná. Mercator, Fortaleza, v. 13, n. 2, p. 91-104, maio/ago. 2014.

CURY, Carlos Roberto Jamil. Legislação educacional brasileira. Rio de Janeiro: DP\&A, 2000.

FAHEL, Murilo Cássio Xavier; FRANÇA, Bruno Cabral; MORAES, Thais. O efeito da condicionalidade educação do Bolsa Família em Minas Gerais: uma avaliação por meio da PAD/MG. Revista Brasileira de Monitoramento e Avaliação, n. 2, p. 4-35, jul./dez. 2011. Disponível em: <https:// www.researchgate.net/profile/Murilo_Fahel2/publication/275716573_O_efeito_da_condicionalidade_educacao_do_Bolsa_Familia_em_Minas_Gerais_uma_avaliacao_por_meio_da_ PADMG/links/554575190cf23ff71686afae/O-efeito-da-condicionalidade-educacao-do-Bolsa-Familia-em-Minas-Gerais-uma-avaliacao-por-meio-da-PAD-MG.pdf>. Acesso em: 2 fev. 2016.

INSTITUTO NACIONAL DE ESTUDOS E PESQUISAS EDUCACIONAIS ANÍSIO TEIXEIRA (INEP). Sinopse Estatística da Educação Básica 2015. Brasília: INEP, 2016. Disponível em: <http:// portal.inep.gov.br/web/guest/sinopses-estatisticas-da-educacao-basica>. Acesso em: 15 dez. 2016.

INSTITUTO NACIONAL DE ESTUDOS E PESQUISAS EDUCACIONAIS ANÍSIO TEIXEIRA (INEP). Censo Escolar 2015. Microdados. Disponível em: <http://portal.inep.gov.br/basica-levantamentos-acessar >. Acesso em: 23 mar. 2016.

INSTITUTO PARANAENSE DE DESENVOLVIMENTO ECONÔMICO E SOCIAL (IPARDES). Mesorregião Geográfica Centro-Sul Paranaense. Curitiba: Instituto Paranaense de Desenvolvimento Econômico e Social, 2004.

MINISTÉRIO DA EDUCAÇÃO (MEC). Sistema Presença. 2015. Disponível em: <http://frequenciaescolarpbf.mec.gov.br/presenca/controller/login/efetuarLogin.php>. Acesso em: 12 fev. 2016.

MINISTÉRIO DO DESENVOLVIMENTO SOCIAL E COMBATE À FOME (MDS). Bolsa Família. Disponível em: <http://www.mds.gov.br/bolsafamilia>. Acesso em: 10 mar. 2016.

. DataSOCIAL: quantidade de beneficiários do Programa Bolsa Família segundo idade. 2013-2015. Disponível em: <http://aplicacoes.mds.gov.br/sagi-data/METRO/metro_ds.php?p_id=74\&p_ibge=41\&p_geo=0>. Acesso em: 14 jul. 2016.

HORTA NETO, João Luiz. Avaliação sem impacto na aprendizagem. In: YANNOULAS, Silvia Cristina (Org.). Política educacional e pobreza: múltiplas abordagens para uma relação multideterminada. Brasília: Líber Livro, 2013. p. 111-36.

SCHNEIDER, G. Política educacional e instrumentos de avaliação: pensando um Índice de Condições Materiais da Escola. 250f. Dissertação (Mestrado em Educação) - Universidade Federal do Paraná (UFPR), Curitiba, 2010. 
SEN, Amartya Desigualdade reexaminada. Tradução de Ricardo Doninelli Mendes. Rio de Janeiro: Record, 2012.

. A ideia de justiça. Tradução de Denise Bottmann e Ricardo D. Mendes. São Paulo: Companhia das Letras, 2011.

YANNOULAS, Silvia Cristina. Literatura recente sobre uma antiga problemática. In:

(Org.). Política educacional e pobreza: múltiplas abordagens para uma relação multideterminada. Brasília: Líber Livro, 2013. p. 25-66.

\section{Sobre as autoras:}

Andréa Barbosa Gouveia: Possui graduação em Pedagogia pela Universidade Federal do Paraná (1995), mestrado (2002) e doutorado (2008) em Educação pela Universidade de São Paulo, Faculdade de Educação, na área de concentração Estado, Sociedade e Educação. Atualmente é professora da Universidade Federal do Paraná onde atua no Núcleo de pesquisa em Políticas Educacionais (NUPE). Está credenciada no Programa de Pós Graduação em Educação da UFPR na linha de pesquisa em Políticas Educacionais. Foi coordenadora do Grupo de Trabalho Estado e Educação da ANPED no período de 2010-2012, vice-presidente Sul da diretoria da ANPED na gestão 2013-2015 e atualmente é Presidente da ANPED - gestão 2015-2017. Tem experiência na área de Educação, com ênfase em Política Educacional, atuando principalmente nos de financiamento da educação, remuneração docente, política educacional em sistemas de ensino. E-mail: andrea-gouveia@uol.com.br

Gabriela Schneider: Possui graduação em Pedagogia pela Universidade Federal do Paraná (2007), mestrado e doutorado em Educação pela mesma universidade na linha de políticas educacionais. É professora no Departamento de Planejamento e Administração Escolar da UFPR onde atua no Núcleo de pesquisa em Políticas Educacionais (NUPE). Tem experiência na área de Educação com ênfase em Políticas e Gestão Educacional e no uso de dados quantitativos, atuando principalmente nos seguintes temas: avaliação educacional, financiamento da educação, condições materiais, indicadores de qualidade e infraestrutura escolar. E-mail: gabriela0905@ hotmail.com

\section{Recebido em março de 2017}

\section{Aprovado para publicação em agosto de 2017}

